\title{
Microheterogeneous systems of micelles and microemulsions as reaction media in chemiluminescent analysis
}

\author{
Jin-Ming Lin, Masaaki Yamada
}

\begin{abstract}
The development of new or enhanced analytical methodologies based on the use of microheterogeneous systems is a very active area of current research. The use of organized surfactant molecular assemblies, such as micelles, reversed micelles and microemulsions, in analytical solution chemiluminescence is steadily increasing because it can change luminescent characteristics and result in a greatly improved analytical performance, in terms of selectivity, sensitivity and experimental convenience. This review focuses on how micelles, reversed micelles and microemulsions may be used to improve the quality of chemiluminescent analytical procedures and gives some applications of these microheterogeneous chemiluminescent systems.
\end{abstract}

(C) 2003 Published by Elsevier Science B.V.

Keywords: Chemiluminescence; Micelle; Microemulsion; Microheterogeneous system; Reversed micelle

\footnotetext{
Jin-Ming Lin* Research Center for Eco-Environmental Sciences, Chinese Academy of Sciences, P.O. Box 2871, Beijing 100085, P.R. China

Masaaki Yamada Department of Applied Chemistry, Graduate School of Engineering, Tokyo Metropolitan University, 1-1 Minami-Ohsawa, Hachioji, Tokyo 192-0397, Japan
}

\section{Introduction}

Chemiluminescence (CL) is the emission of light from chemical reactions at room temperature and is observed in gas, liquid and solid phases. Two primary requirements for such emission are: 1) the emission of energy released should be higher than that of the electronically excited product or intermediate molecule; and, 2) the product must be a fluorescent molecule so that the transformation of the excited molecule to the ground state is accompanied by visible light emission, or the reaction mixture has to include energy acceptor molecules with fluorescent properties [1].

As a rule, CL appears during oxidation reactions or free-radical recombination. In most cases the quantum yield of CL,
$\Phi_{\mathrm{CL}}$, which is the ratio of the number of light quanta of emitted molecules to the number of analyte molecules consumed, does not exceed $0.1-0.001 \%$, but for some CL systems, e.g., the special substituted oxiamide or dioxetane intermediate, it can reach as high as 30\% [2]. There are also several special CL systems in living cells with high quantum yields from 1 to $100 \%$, where luminescence appears during the oxidation of the highly specific substrate luciferin, catalyzed by the enzyme luciferase. In bioluminescence having the correct reaction medium and microenvironment is vital to obtain a high quantum yield. This suggests that it should be possible to improve the quantum yield of CL if a special microheterogeneous system could be developed as the CL reaction media.

The popularity of CL as a detection system relates to its high sensitivity and the simple instrumentation required. No light source is required for CL as compared to fluorimetry and absorption techniques. CL has been widely used in clinical chemistry, biochemistry, environmental chemistry, etc. Its rapid development is reflected in the great numbers of publications devoted entirely to the discussion of CL [3-10]. Despite being highly sensitive the CL method cannot be used to determine most analytes directly. Many analysts have made great efforts to improve not only the CL intensity but also the selectivity. Their efforts are reflected in the many new homogeneous and 
heterogeneous CL systems reported. In the present paper, micro-heterogeneous CL systems, including the uses of micelles, reversed micelles and microemulsion of surfactant aggregate are reviewed.

\section{Principle of CL analysis}

As described in the introduction section, the phenomenon of CL can be defined in simplistic terms: chemical reactions that emit light. The chemical reaction produces energy in sufficient amount (approximately 300 $\mathrm{kJ} / \mathrm{mol}$ for blue light emission and $150 \mathrm{~kJ} / \mathrm{mol}$ for red light emission) to induce the transition of an electron from its ground state to an excited electronic state. This electronic transition is often accompanied by vibrational and rotational changes in the molecule. In organic molecules, transitions from a $\pi$ bonding to a $\pi^{*}$ anti-bonding orbital $\left(\pi \rightarrow \pi^{*}\right)$ or from a non-bonding to an anti-bonding orbital $\left(\mathrm{n} \rightarrow \pi^{*}\right)$ are most frequently encountered. The return of the electron to the ground state with emission of a photon is thus called CL. The excited molecule can also lose energy by undergoing chemical reaction, collisional deactivation, internal conversion or inter-system crossing. These radiationless processes are undesirable from an analytical point of view when they compete with CL. The chemical reaction of the molecules $\mathrm{A}$ and $\mathrm{B}$ to form $\mathrm{P}^{*}$, an intermediate or product in an electronically excited state, is shown as the following scheme.

$\mathrm{A}+\mathrm{B} \stackrel{\text { Chemical }}{\rightarrow} \stackrel{\text { reaction }\left(\Phi_{\mathrm{R}}\right)}{\rightarrow} \stackrel{\text { Excitation }\left(\Phi_{\mathrm{EX}}\right)}{\rightarrow} \mathrm{P}^{*}$

There are two possible pathways for CL emission, either directly from the excited molecule $\left(\mathrm{P}^{*}\right)$,

$\mathrm{P}^{*} \stackrel{\Phi_{\mathrm{EM}}}{\rightarrow} \mathrm{P}+\mathrm{h} v\left(\right.$ fluorescent emission from $\left.\mathrm{P}^{*}\right)$

or indirectly where the energy is transferred from $\mathrm{P}^{*}$ to a fluorescent emitter.

When transferring the energy of the excited molecule, $\mathrm{P}^{*}$, to another fluorescent compound, F, the emission can be amplified, $\mathrm{F}$ is therefore also called a CL enhancer and the process is named enhancement of the CL reaction.

$\mathrm{P}^{*}+\mathrm{F} \stackrel{\Phi_{\mathrm{ET}}}{\rightarrow} \mathrm{P}+\mathrm{F}^{*}($ energy transfer $)$

$\mathrm{F}^{*} \stackrel{\Phi_{\mathrm{F}}}{\rightarrow} \mathrm{F}+\mathrm{h} v$ (fluorescence emission from $\mathrm{F}^{*}$ )

For direct CL, the ratio of photons emitted to the number of analyte molecules consumed is the quantum yield, $\Phi_{C L}$, that is the product of three ratios concerned with three different reaction processes:
$\Phi_{\mathrm{CL}}=\Phi_{\mathrm{R}} \cdot \Phi_{\mathrm{EX}} \cdot \Phi_{\mathrm{EM}}$

where $\Phi_{\mathrm{R}}$ is the fraction of reacting molecules giving an excited molecule (product or intermediate) and amounts to the yield of the chemical reaction; $\Phi_{\mathrm{EX}}$ is the fraction of such molecules in an electronically excited state and relates to the efficiency of the excitation; and, $\Phi_{\mathrm{EM}}$ is the fraction of these excited molecules that return to the ground state by emitting a photon. The CL intensity, $\mathrm{I}_{\mathrm{t}}$, at time, $\mathrm{t}$, is:

$\mathrm{I}_{\mathrm{t}}=-\Phi_{\mathrm{CL}} \mathrm{d}[\mathrm{A}] / \mathrm{d}_{\mathrm{t}}$

and the total light emission, $\mathrm{W}$, is given by:

$\mathrm{W}=\int \mathrm{I}_{\mathrm{t}} \mathrm{d}_{\mathrm{t}}=\Phi_{\mathrm{CL}}[\mathrm{A}]_{\mathrm{o}}$

where $[A]_{\mathrm{o}}$ is the initial concentration of the analyte, which means that, at the same concentrations of analyte and other reactants, the total light emission depends on $\Phi_{\mathrm{CL}}$. The CL intensity therefore depends on both $\Phi_{\mathrm{CL}}$ and the concentration of the analyte.

For indirect CL emission, the CL intensity can be expressed similarly to Equation (2):

$\mathrm{I}_{\mathrm{t}}=-\Phi_{\mathrm{CL}} \mathrm{d}[\mathrm{C}] / \mathrm{d}_{\mathrm{t}}$

But here:

$\Phi_{\mathrm{CL}}=\Phi_{\mathrm{R}} \cdot \Phi_{\mathrm{EX}} \cdot \Phi_{\mathrm{ET}} \cdot \Phi_{\mathrm{F}}$

where $\Phi_{\mathrm{ET}}$ is the quantum yield of the energy transfer from the excited molecule, $\mathrm{P}^{*}$, to the enhancer F. $\Phi_{\mathrm{F}}$ is the fluorescent quantum yield of the excited molecule, $\mathrm{F}^{*}$, and $\mathrm{C}$ is the concentration of analyte.

As shown in Fig. 1, when the CL reaction is first order, the relationship of the CL intensity and the reaction time can be expressed as the following equation:

$\mathrm{I}_{\mathrm{t}}=\Phi_{\mathrm{CL}} \mathrm{k}_{1}[\mathrm{~A}]=\Phi_{\mathrm{CL}} \mathrm{k}_{1}[\mathrm{~A}]_{0} \exp \left(-\mathrm{k}_{1} \mathrm{t}\right)$

where $\mathrm{k}_{1}$ is the kinetic constant of CL reaction, and it is usually decided by the slowest reaction step.

In flow-injection analysis, the detectable CL intensity is often measured as the peak height, $I_{t}$, especially the maximum peak height, $\mathrm{I}_{\max }$. The reaction time in this case will be the interval between mixing the sample with the CL reagent and the emission of light in the flow cell; this is usually very brief, so that:

$\mathrm{I}_{\mathrm{t}}=\Phi_{\mathrm{CL}} \mathrm{k}_{1}[\mathrm{~A}]_{0}$

$\mathrm{I}_{\mathrm{t}}=\mathrm{I}_{\mathrm{t}} / \mathrm{D}=\Phi_{\mathrm{CL}_{\mathrm{L}}} \mathrm{k}_{1}[\mathrm{~A}]_{0} / \mathrm{D}$, where $\mathrm{D}$ is the dispersion of the sample in the flow injection manifold. 
In order to obtain a high sensitivity for the determination of $\mathrm{A}$, both $\Phi_{\mathrm{CL}}$ and $\mathrm{k}_{1}$ are important. Many analysts have made a great effort to improve the CL quantum yield and the reaction velocity, e.g., to select the catalyst, solvent, temperature, surfactant, etc. One of the effective methods is to develop microheterogeneous systems. A great number of these systems have been reported in the last two decades This review summarizes microheterogeneous systems of micelles and microemulsions as CL reaction media.

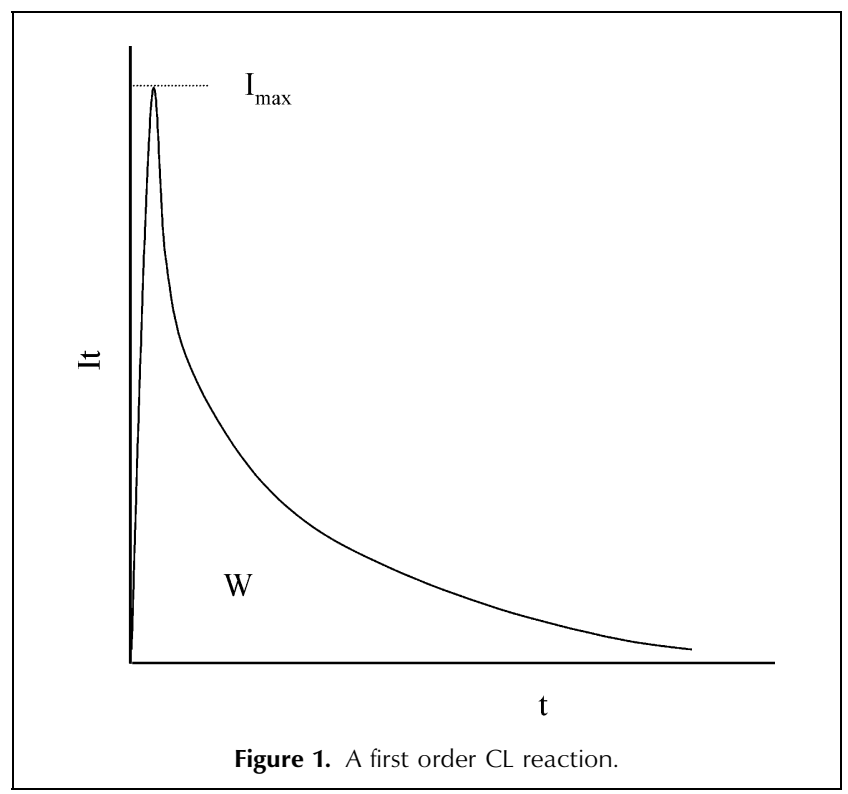

\section{Effects of microheterogeneous media on CL reactions}

The term "microheterogeneous system" often refers to a small aggregate system of molecules within the solvent or other surrounding medium. Based on this definition, microheterogeneous systems can be either organic or inorganic (Fig. 2) [11].

The former include surfactants or lipid molecules dispersed in aqueous solution with or without additional surfactants: normal and reversed micelles; microemulsions; lipid bilayers; mono-layer and multi-layer assemblies; and, some compounds, e.g., cyclodextrins and calixarenes, with a toroid or hollow truncated cone. Most of these aggregates are self-assembling. The important points to bear in mind are the presence of distinct hydrophobic and hydrophilic microphases, associated interfaces, and the dynamic nature of their aggregation.

Inorganic microheterogeneous systems include colloidal dispersions of inorganic solids: metals; metal oxides; clays; minerals; and, zeolites (but these are not often used in CL).

This review focuses on microheterogeneous systems based on surfactants, especially, normal micelles, reversed micelles and microemulsions. These organized assemblies may exhibit several peculiar properties as reaction media [12-14]. There are several potentially significant advantages in using micellar systems as the medium for analytical CL measurements. First, the solubilization introduces two new situations that can influence the reaction rates: changes in the local distribution of solute (reactants); and, surface/interface

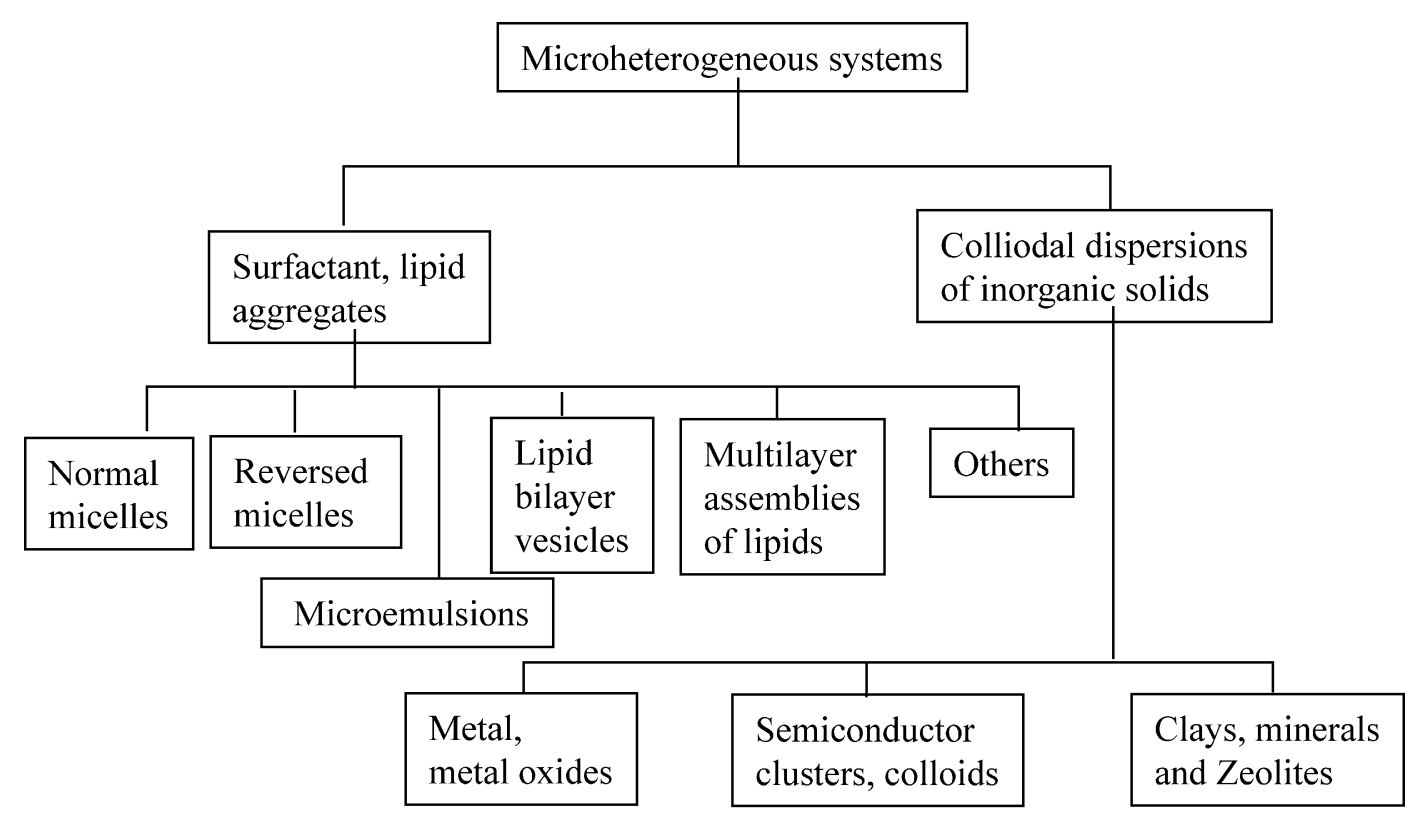

Figure 2. Various microheterogeneous systems of interest. 
effects. Second, they confer the ability to alter the CL reaction rate and/or excitation efficiency via manipulation of the type and the concentration of surfactant micelle present. This conveniently allows the analyst to improve sensitivity and/or extend the range of the calibration curves as required. Third, the use of micelles to lower the $\mathrm{pH}$ required for efficient CL may be very useful in certain CL assays, particularly those based on enzymatic conversion of the analyte into a species that can subsequently be determined via CL. The use of micelles to control solubility, reactivity, sensitivity, and $\mathrm{pH}$ requirements in CL assays provides a convenient alternative to methods currently employed to achieve these same goals. However, the use of micellar enhanced CL also has disadvantages, especially the imprecision obtained with batch methods. With the development of the flow-injection method, this deficiency can be overcome. In view of the number and types of different micellar systems available, it should be possible to find a suitable micelle to provide enhanced CL measurement of virtually any analyte of interest.

\section{Microheterogeneous CL systems}

\subsection{Normal micelles}

Normal micelles are assemblies of surfactants, or surface-active agents, i.e., amphiphiles that have ionic or polar head groups and hydrophobic residues that are typically n-alkyl groups formed when a certain minimum concentration (called the critical micelle concentration, CMC) is reached. The competition between hydrophobic and hydrophilic interactions in the micelle systems are simple when compared to that in biological membranes. Many thermodynamic, transport, and spectroscopic properties show a distinct change in behavior with concentration around the CMC [15].

Aqueous micelles possess many unique and advantageous properties, which should better facilitate analytical CL measurements. They have been shown to:

1. solubilize, concentrate, and organize solutes/ reactants;

2. alter effective microenvironments (i.e., polarity, viscosity, acidity) about solubilized species;

3. alter spectral parameters of solutes and the quantum efficiencies of their reactions;

4. alter chemical and photophysical pathways and rates; and,

5. be chemically stable, optically transparent, and relatively nontoxic.

These micellar properties have been successfully employed to enhance a variety of other analytical techniques $[13,14,16]$. The early reports $[17,18]$ dealing with the use of CL reactions in micellar medium were not concerned with analysis; the CL reactions were instead used as probes for the study of micellar structure and/or dynamics. CL generated from methylene 10-dodecylactidan and cypridina luciferin was not detected in water, but observed in the presence of surfactant micelles.

The first analytical application of a CL reaction in a micellar medium was reported by Yamada and Suzuki [19]. The copper-catalyzed CL of 1,10-phenanthroline was highly enhanced in the presence of some cationic surfactant micelles, and this reaction system was used for the highly sensitive determination of copper(II) by flow-injection analysis. The CL seen, with an emission maximum in the region of 445-450 nm, results from the oxidative destruction of 1,10-phenanthroline during the catalytic decomposition of hydrogen peroxide by the copper-1,10-phenanthroline complex and the mechanism was developed as can be seen in Fig. 3.

A micelle formed from a cationic surfactant has a hydrophobic center, but allows ionic interactions at the outside surface. The 1,10-phenanthroline molecules concentrated in the center of the micelles, and the superoxide anionic radicals were attracted onto the micellar surface, which made the interaction between 1,10-phenanthroline and the superoxide radical easy and effective. The limit of the determination for copper(II) was $0.3 \mathrm{pg}$, and this method was developed to determine trace amounts of copper in tap water [20], rabbit's lenses [21] and seawater [22].

Fe(III) [23], Co(II) [24] and Zn(II) [25] also catalyzed the 1,10-phenanthroline- $\mathrm{H}_{2} \mathrm{O}_{2}$ reaction in micellar solution, and the reaction was used to determine these ions.

Another early application of micelles in CL was the flavin mononucleotide-sensitized CL of sulfur dioxide [26,27], which was found to be enhanced by some cationic and nonionic surfactant molecules, respectively.

Hinze et al. have reported on the use of micelles to improve the analytical characteristics of specific CL assays based on the use of lophine, luminol, and lucigenin [28]. They demonstrated the first comprehensive analytical application of micelle-mediated CL analysis. Several significant advantages of the new micelleenhanced technique were expounded, making CL an even more attractive method.

The use of sub-micellar concentrations of sodium dodecyl sulfate has been shown to eliminate precipitation difficulties encountered in stopped-flow CL assays using lucigenin [29].

The effects of halide ions, such as bromide and chloride, on the CL intensity emitted from the lucigenin CL reaction with adrenaline in cationic micellar solutions were studied by Kamidate et al. [30,31]. The CL intensity increased with an increase in the carbon number of the alkyl group [30] when the surfactants 
were under the same concentration. However, the degree of quenching by chloride ions was dependent on the carbon number in the alkyl group of the surfactant reagents used. This can related to their CMCs, which are $1.3 \times 10^{-3} \mathrm{M}$ for hexadecyltrimethylammonium chloride (CTAC), $4.5 \times 10^{-3} \mathrm{M}$ for tetradecyltrimethylammonium chloride (TTAC) and $2.0 \times 10^{-2} \mathrm{M}$ for dodecyltrimethylammonium chloride (DTAC), respectively. Along with a decrease in carbon number of alkyl group, the CMC and thus the concentration of surfactant micelles increased. The concentration of chloride ions increases simultaneously under these conditions. Consequently, the degree of the quenching by chloride ions may increase with a decrease in the carbon number of the alkyl group of surfactant reagents. However, the maximum CL intensity in such C16 surfactants as hexadecyltrimethylammonium hydroxide $(\mathrm{CTAOH}), \mathrm{CTAC}$, and hexadecyltrimethyl- ammonium bromide (CTAB), were not affected by the counter-ions of the surfactant reagents. This result may be interpreted by taking into account their CMCs. That is, the CL intensity reached a maximum value without suffering from the quenching effect of halide ions on the CL intensity, since the CMCs for CTAC and CTAB are well below the concentrations required for quenching by halide ions.

With CTAB or CTAC micelles, the inert chloride or bromide counter-ion competes with and displaces reactive counter-ions (such as the hydroxide ion) from the micellar surface and reduces reaction rates [32]. For example, the selectivity coefficients for hydroxide exchange in cationic alkyltrimethylammonium surfac- tant micelles, $\mathrm{K}_{\mathrm{OH} / \mathrm{X}}$, are $0.02-0.22$ and $0.023-0.08$ for $\mathrm{X}=\mathrm{Cl}^{-}$and $\mathrm{Br}^{-}$, respectively. Thus, for bimolecular reactions involving the hydroxide ion and neutral substrates, the rate enhancement (and CL intensity) observed in CTAC or CTAB micelles is not as great as it could be because of this competitive ion exchange. Some of the CL systems carried out in micellar media are summarized in Table 1, different aqueous micelles have been used to improve lucigenin [28-32,46], luminol $[33,34,47]$ and peroxyoxalate $[36,48]$ CL reactions. These systems indicated that with the use of micelles the sensitivity and selectivity of the CL analysis were improved. This suggests the potential of these systems for analytical applications will continue to be studied.

\subsection{Reversed micelles}

In CL measurements, an interesting development of analytical significance is the incorporation of reverse micelles into the detection system. Results from different CL studies indicate many advantages, including sensitivity and improved selectivity in the reversed micellar system [49].

The center of the reversed micellar core, which provides a unique, versatile reaction field, is referred to as a microreactor [50]; it is filled with water molecules surrounded by surfactant polar heads, while the hydrophobic chains are directed into the bulk non-polar organic phase. Until 1987, almost all of the micelleenhanced analytical procedures reported had utilized normal aqueous micelle systems. Consideration of so-called reversed micelles in CL measurements or

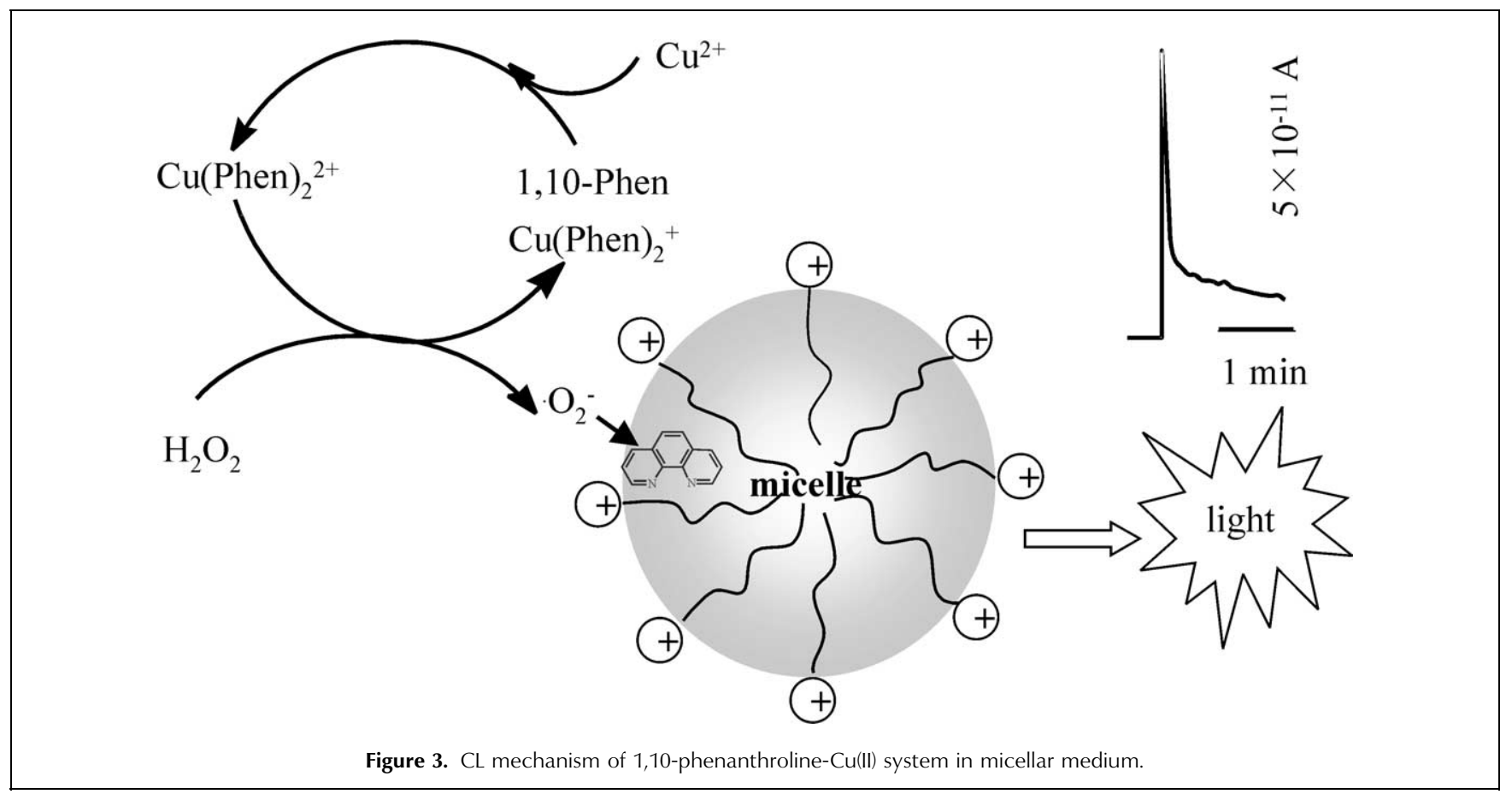


chemical analysis in general seemed to have been overlooked. Hoshino and Hinze [51] first described in the results of their comprehensive study of the effect of a cationic reversed micellar system (i.e., CTAC in $6: 5(\mathrm{v} / \mathrm{v})$ chloroform-cyclohexane containing specified amounts of water) upon the spectral and physical properties of the CL reagent, luminol, and its primary emitter, 3-aminophthalic acid. Additionally, the use of the CTAC reversed micellar system as a medium for the luminol chemiluminescent assay for hydrogen peroxide was evaluated and the analytical results were compared and contrasted with those obtained in bulk water alone. Such a reversed micellar solution has been used to amplify the CL of luminol-hydrogen peroxide system under mild $\mathrm{pH}(7.8-9.1)$ conditions [51,52]. The significance of reverse micelles in CL analysis is considered to result from their unique structure (size/shape) and composition. Although not demonstrated, it is believed that reversed micellar mediated CL reactions occur at surfactant-water interfaces [14,49]. In addition to the advantage of sensitivity, these microreactors can transfer species of experimental interest quantitatively into water [53-55].

Because of the catalytic behavior of different metal ions and the effectiveness of reverse micelles in CL reactions, Fujiwara et al. used reversed micellar mediated CL reactions to develop new methods for off/on-line trace-level quantification of gold(III) [5659], rhodium(III) [60], iron(III) [54,61], iron(II) [61], vanadium(IV) [55,62], atropine [63] and iodide and/or iodine [64].

Most probably via ion-pair formation in the extraction process, gold(III) was transferred as the tetrachloroaurate ion from aqueous solution into chloroform-containing tri- $n$-octylphosphine oxide [57]. The post-extraction step was directly coupled to a reversed micellar mediated CL reaction system, and the resulting solvent extraction/reversed micellar mediated CL hybrid method was then applied to the determination of gold in industrial samples $[57,58]$.

The combination of CL flow-injection methods with reversed micelles has been used for the determinations of primary amines and amino acids [65-67].

The Schiff bases derived from phenylacetadehyde in methanol for amines and sodium bis(2-ethylhexyl)sulphosuccinate (AOT) reversed micellar solution for amino acids were found to produce strong CL when oxidized with iron(II) and hydrogen peroxide (Fenton's reagent). The determination limits were $1.5 \times 10^{-8} \mathrm{M}$ for n-hexylamine and $1.4 \times 10^{-7} \mathrm{M}$ for alanine [65]. A study of the mechanism indicated that the acceleration of Schiff-base formation depended on both the water-tosurfactant ratio in the reserved micellar solution and the hydrophobicity of the amino acids $[66,67]$.

Table 1. Summary of $\mathrm{CL}$ analysis using normal micelles as reaction media

\begin{tabular}{|c|c|c|c|c|}
\hline Reaction medium & $\mathrm{CL}$ reaction & Analyte & Detection limit & Ref. \\
\hline CTAB & Luminol/peroxidase & Glucose & $1 \times 10^{-8} \mathrm{M}$ & [33] \\
\hline Triton X 100 & Luminol $/ \mathrm{NO}_{2} / \mathrm{SO}_{3}^{2-} / \mathrm{OH}^{-}$ & $\mathrm{NO}_{2}$ & $3 \mathrm{ppb}(\mathrm{v} / \mathrm{v})$ & [34] \\
\hline $\mathrm{CTAOH}$ & Lucigenin $/ \mathrm{H}_{2} \mathrm{O}_{2}$ & Biological reductants & $2.3 \mathrm{mg} / \mathrm{l}$ fructose & {$[32]$} \\
\hline СТАOH & Lucigenin $/ \mathrm{NaIO}_{4} / \mathrm{OH}^{-}$ & Adrenaline & $1 \times 10^{-8} \mathrm{M}$ & {$[31]$} \\
\hline $\mathrm{CTAOH}$ & Lucigenin/Adrenaline $/ \mathrm{OH}^{-}$ & Adrenaline & & [30] \\
\hline SDS & Lucigenin/glucuronic acid & Glucuronic acid & & [29] \\
\hline SDS & Lucigenin $/ \mathrm{OH}^{-}$ & Ascorbic acid, etc. & & {$[28]$} \\
\hline CTAHO & Lucigenin $/ \mathrm{NaIO}_{4}$ & Epinephrine & & [35] \\
\hline Arkopal N-300 & TCPO/perylene $/ \mathrm{H}_{2} \mathrm{O}_{2}$ & Perylene & $\mathrm{nM}$ level & {$[36]$} \\
\hline CTAB & 1,10-Phen/ $\mathrm{H}_{2} \mathrm{O}_{2} / \mathrm{Cu}^{2+}$ & $\mathrm{Cu}^{2+}$ & $0.3 \mathrm{pg} / 20 \mu \mathrm{l}$ & {$[19,20]$} \\
\hline CTAB & 1,10-Phen $/ \mathrm{H}_{2} \mathrm{O}_{2} / \mathrm{Co}^{2+} /$ Nucleosides & Nucleosides and their derivatives & $68 \mathrm{pmol} / 10 \mu \mathrm{l}$ & [37] \\
\hline TSAC & 1,10-Phen $/ \mathrm{H}_{2} \mathrm{O}_{2} / \mathrm{Zn}^{2+}$ & $\mathrm{Zn}^{2+}$ & $2.3 \times 10^{-8} \mathrm{M}$ & {$[25]$} \\
\hline \multirow[t]{2}{*}{ CTAB } & 1,10-Phen $/ \mathrm{H}_{2} \mathrm{O}_{2} / \mathrm{Fe}^{2+}, \mathrm{Co}^{2+}$ & $\mathrm{Fe}^{2+}$ & $0.1 \mathrm{ppb}$ & [23] \\
\hline & & $\mathrm{Co}^{2+}$ & $5 \mathrm{ppb}$ & {$[24]$} \\
\hline Triton X-45 & $\mathrm{Ru}(\mathrm{bpy})_{3}^{3+}$ & Codeine & $8.3 \times 10^{-7} \mathrm{M}$ & [38] \\
\hline SDS (Triton X 100 CTAB) & $\mathrm{OS}(\mathrm{bpy})_{3}^{2+}$ & ECL study & & [39] \\
\hline CTAB & Dibromoalizarin violet $/ \mathrm{H}_{2} \mathrm{O}_{2} / \mathrm{Co}^{2+}$ & $\mathrm{Co}^{2+}$ & $4 \mathrm{pg} / \mathrm{ml}$ & {$[40]$} \\
\hline CTAB & $\mathrm{CLPF} / \mathrm{H}_{2} \mathrm{O}_{2} / \mathrm{Co}^{2+}$ & $\mathrm{Co}^{2+}$ & $0.07 \mathrm{ng} / \mathrm{ml}$ & {$[41]$} \\
\hline CTAB & $\beta$-Nitrostyrene/Fluorescein/ $\mathrm{Cu}^{2+}$ & $\beta$-Nitrostyrene & $0.1 \mathrm{ng} / 20 \mu \mathrm{l}$ & {$[42]$} \\
\hline \multirow[t]{2}{*}{ TDBAC } & $\mathrm{FMN} / \mathrm{Cr}(\mathrm{III}) / \mathrm{H}_{2} \mathrm{O}_{2}$ & $\mathrm{Cr}(\mathrm{III})$ & $5 \times 10^{-8} \mathrm{M}$ & {$[43]$} \\
\hline & & $\mathrm{Cr}(\mathrm{VI})$ & $1 \times 10^{-5} \mathrm{M}$ & \\
\hline Tween 80 & Rhodamin $6 \mathrm{G} / \mathrm{O}_{2} / \mathrm{H}^{+}$ & Sulfite & $0.03 \mathrm{mg} / \mathrm{l}$ & {$[44]$} \\
\hline Tween 85 & $\mathrm{FMN} / \mathrm{KmnO}_{4} / \mathrm{SO}_{2}$ & $\mathrm{SO}_{2}$ & $3 \mathrm{ppb}$ & {$[26]$} \\
\hline SDBS & $\mathrm{IO}_{4}^{-} / \mathrm{H}_{2} \mathrm{O}_{2}$ & SDBS & $8.3 \times 10^{-8} \mathrm{~g} / \mathrm{ml}$ & {$[45]$} \\
\hline
\end{tabular}


The use of AOT reversed micelle as a medium for the determination of fluorophors was reported [68]. Both cationic CTAC and anionic AOT reversed micelles were compared.

Table 2 lists some of the reported applications of reversed micelle media in CL. It is surprising to find that until now almost all these systems have been based on CTAC reversed micelles formed in $\mathrm{CHCl}_{3}$-cyclohexane/ water solvent, with the exception of a few AOT/1-buta$\mathrm{nol} /$ cyclohexane systems. This perhaps results from the use of organic solvents and the instability of reversed micelles, making their use difficult in flow-injection analysis. More effective reversed micellar systems and further development of this method are required.

\subsection{Microemulsion}

A microemulsion is an isotropic, optically clear dispersion of oil-in-water $(\mathrm{O} / \mathrm{W})$ or water-in-oil $(\mathrm{W} / \mathrm{O})$, where "oil" is a hydrocarbon. The name "microemulsion" derives from the fact that oil droplets in $\mathrm{O} / \mathrm{W}$ systems or water droplets in $\mathrm{W} / \mathrm{O}$ systems are small $\left(50-500 \mathrm{~A}^{\circ}\right)$. Like micelles, microemulsions serve as unique compartmentalized environments for different kinds of reactions, and both moderate and high-rate accelerating effects have been observed [70-72]. In such media, the interface between the water and oil possesses a physical nature widely different from that of an aqueous or nonaqueous continuum and has the power to significantly influence the kinetic process, depending on the locations of the interacting species in the compartment.

Compared to micelles, microemulsions are versatile because the compartment sizes can be altered at will in both the absence and the presence of additives. They are thermodynamically stable colloidal dispersions of surfactant molecules in either oil or water [73,74]. Surfactants facilitate emulsification by reducing interfacial tension and stabilization by introducing doublelayer forces and/or solvation forces between dispersed particles.

Microemulsions have proved to be interesting as reaction media for many different areas of chemistry or biochemistry because of the presence of a local organized structure of aqueous and organic microdomains within a perfectly macroscopically homogeneous, thermodynamically stable, isotropic solution. They provide unique, variable reaction media depending on the $\mathrm{W} / \mathrm{O}$ or the $\mathrm{O} / \mathrm{W}$ ratios and have been used to study keratin cystine reactivity [75], organic reactivity [76] and as reaction media for the synthesis of surfactants [77-79] as well as for analytical chemistry $[80,81]$.

However, surprisingly, only very few reports have been published on the use of microemulsions as media for CL reactions [82-90], including five original papers [82-86] and four patent reports [87-90].

The fast hydrolysis reactions that peroxalate esters undergo in protic solution have been studied using a microemulsion medium to dissolve the peroxyoxalatetype reagents. It is well-known that peroxyoxalate CL reactions, involving the oxidation of an oxalic acid derivative by hydrogen peroxide in the presence of a suitable fluorophor [5,91], have been used analytically for the measurement of many substances [4-10]. However, in many of these applications, some major problems are encountered. Most oxalic acid derivatives are only soluble and effective in organic solvents, and that causes irreproducible mixing when measured in aqueous samples. Although water-soluble derivatives have been reported, efficiencies are very low. In many

Table 2. Summary of $\mathrm{CL}$ analysis using reverse micelles as reaction media

\begin{tabular}{|c|c|c|c|c|}
\hline Reaction medium & CL system & Analyte & Detection limit & Ref. \\
\hline $\begin{array}{l}\text { CTAC/Dichloromethane/cyclohexane } \\
(1: 1 \mathrm{v} / \mathrm{v}) / \text { water }\left(0.3 \mathrm{M} \mathrm{Na}_{2} \mathrm{CO}_{3}\right)\end{array}$ & $\begin{array}{l}\text { Luminol/Tetrachloroaurate/ } \\
\text { Atropinium }\end{array}$ & Atropine & $1 \mathrm{ng} / \mathrm{ml}$ & [62] \\
\hline $\mathrm{CTAC} / \mathrm{CHCl}_{3} /$ cyclohexane/water & Luminol/VO(acac) $)_{2}$ & $\mathrm{~V}(\mathrm{IV})$ & $0.05 \mathrm{ng} / \mathrm{ml}$ & [62] \\
\hline $\mathrm{CTAC} / \mathrm{CHCl}_{3} /$ cyclohexane/water (pH 11.5) & Luminol/2-iodosobenzoate & lodide & $0.02 \mathrm{ng} / \mathrm{ml}$ & [64] \\
\hline $\mathrm{CTAC} / \mathrm{CHCl}_{3} /$ cyclohexane/water $(0.1 \mathrm{M} \mathrm{NaOH})$ & Luminol $/ \mathrm{H}_{2} \mathrm{O}_{2} / \mathrm{Fe}(\mathrm{III})$ & $\mathrm{Fe}(\mathrm{III})$ & $5 \mathrm{ng} / \mathrm{ml}$ & [61] \\
\hline $\mathrm{CTAC} / \mathrm{CHCl}_{3} /$ cyclohexane/water $\left(0.2 \mathrm{Na}_{2} \mathrm{CO}_{3}\right)$ & Luminol $/ \mathrm{O}_{2} / \mathrm{Rh}(\mathrm{III})$ & $\operatorname{Rh}(I I I)$ & $50 \mathrm{ng} / \mathrm{ml}$ & [60] \\
\hline $\mathrm{CTAC} / \mathrm{CHCl}_{3} /$ cyclohexane/water (carbonate buffer) & Luminol/AuCl- & $\mathrm{Au}(\mathrm{III})$ & & [58] \\
\hline $\mathrm{CTAC} / \mathrm{CHCl}_{3} /$ cyclohexane/water (carbonate buffer) & Luminol/Tetrachloroaurate/Au(III) & $\mathrm{Au}(\mathrm{III})$ & $10 \mathrm{pg} / \mathrm{ml}$ & [56] \\
\hline $\mathrm{CTAC} / \mathrm{CHCl}_{3} / \mathrm{cyclohexane} /$ water $\left(0.2 \mathrm{M} \mathrm{Na}_{2} \mathrm{CO}_{3}, \mathrm{pH} 11.5\right)$ & Luminol/Fe(oxine) ${ }_{3} / \mathrm{H}_{2} \mathrm{O}_{2}$ & $\mathrm{Fe}(\mathrm{III})$ & $0.4 \mathrm{ng} / \mathrm{ml}$ & [54] \\
\hline 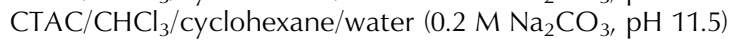 & Luminol/iodine & lodine & $50 \mathrm{pg} / \mathrm{ml}$ & [53] \\
\hline $\mathrm{CTAC} / \mathrm{CHCl}_{3} /$ cyclohexane/water $(\mathrm{pH}$ 7.8-9.1) & Luminol $/ \mathrm{H}_{2} \mathrm{O}_{2}$ & $\begin{array}{l}\mathrm{H}_{2} \mathrm{O}_{2} \\
\text { Glucose }\end{array}$ & $\begin{array}{l}6.4 \times 10^{-7} M \\
1 \times 10^{-4} M\end{array}$ & $\begin{array}{l}{[51]} \\
{[52]}\end{array}$ \\
\hline $\mathrm{CTAC} / \mathrm{CHCl}_{3} /$ water & $\begin{array}{l}\mathrm{TCPO} / \text { perylene } / \mathrm{H}_{2} \mathrm{O}_{2} / \\
\text { ascorbic acid }\end{array}$ & Ascorbic acid & $5 \times 10^{-8} \mathrm{M}$ & [69] \\
\hline AOT & Phenylacetadehyde (PAA) & $\mathrm{N}$-Hexlamine & $1.5 \times 10^{-8} \mathrm{M}$ & [67] \\
\hline AOT & Phenylacetadehyde (PAA) & Alanine & $1.7 \times 10^{-7} \mathrm{M}$ & [65] \\
\hline \multirow[t]{2}{*}{ AOT(CTAC)/1-butanol/cyclohexane } & $\mathrm{TCPO} / \mathrm{H}_{2} \mathrm{O}_{2} / \mathrm{ANS}(\mathrm{RhB})$ & ANS & $\begin{array}{l}2 \times 10^{-8} \mathrm{M} \text { (CTAC) } \\
7 \times 10^{-8} \mathrm{M} \text { (AOT) }\end{array}$ & [68] \\
\hline & & RhB & $1 \times 10^{-6} \mathrm{M}$ (CTAC) & \\
\hline
\end{tabular}


cases, the rates of the CL reaction in an aqueous system are very fast, resulting in imprecise measurements.

Thompson et al. [82] studied several microemulsion systems that contained various fluorophores and oxalate esters. They showed that CL could be obtained in microemulsions based on ionic and non-ionic surfactants, that the emission was a pseudo-first-order process, and that the light intensity was dependent on microemulsion formation.

Using a phase diagram, Cohen and Magdassi [84] studied the effect of the phase composition of the microemulsion on CL, the phase comprising Triton X-100, 2butanol, toluene, and water. The CL intensity of light, $I_{0}$, and $t_{1 / 2}$ were found to depend on both reactant concentrations and phase composition. The light intensity is inversely proportional to $t_{1 / 2}$ when the amounts of reactants are constant. The transition from $\mathrm{W} / \mathrm{O}$ emulsion to $\mathrm{W} / \mathrm{O}$ microemulsion is also reflected in CL intensity and $\mathrm{t}_{1 / 2}$; often CL intensity is stronger and CL signals are sharper in the microemulsion systems.

A CL immunoassay in microemulsion was reported by Kamyshny and Magdassi [85]. Dissolving the particles, which were formed from a special interaction of an antibody with an antigen preadsorbed onto fluorescer (perylene) microparticles in a microemulsion-forming mixture containing TCPO in toluene (oil phase) and $\mathrm{H}_{2} \mathrm{O}_{2}$ in Triton X-100/2-butanol/water, leads to CL.

Recently, we reported [86] a surfactantless $\mathrm{O} / \mathrm{W}$ microemulsion medium, water/n-hexane/2-propanol, that was evaluated for sensing free chlorine based on luminol CL under basic and unbuffered conditions. Under unbuffered conditions, free chlorine provided strong light emission in the microemulsion medium. Even under unbuffered conditions, the microemulsion medium provides sample signals as high as those in basic aqueous solution. Normal and reversed micellar solutions were compared with the microemulsion, and both micelle systems appeared to be useful media.

The CL reaction of luminol was carried out under unbuffered conditions with transition metal ions, e.g., $\mathrm{Cu}^{2+}, \mathrm{Fe}^{2+}, \mathrm{Co}^{2+}$ and $\mathrm{Mn}^{2+}$, not providing appreciable signals in the microemulsion medium, the signals being as low as those in water. This system was directly used to determine free chlorine in tap water. However, because the interface of microemulsion is affected by many conditions, e.g., temperature, composition, pressure, etc., it is difficult to control the formation of microemulsion even under the same conditions. This is one of the reasons for microemulsion not being generally used in CL analysis.

\section{Conclusions}

This is the first review of the use of microheterogeneous systems as media in CL analysis. The high sensitivity and the simple instrumentation required for CL determinations mean that extensions of its applications are continually being sought. New CL systems being reported are concerned with surfactants because the use of micelles as the CL medium greatly improved the CL intensity and selectivity. However, the applications of micelles and microemulsions in CL are relatively few because the mechanism for micelle formation is not fully understood and it is difficult to obtain a suitable micelle for a specific CL reaction. Further research into the application of microheterogeneous media and interface interactions will allow new CL analysis to be developed.

\section{Acknowledgements}

This work was partially supported by the National Science Fund for Distinguished Young Scholars of China (No. 20125514), a grant-in-aid for scientific research from Japan Society for Promotion of Science (13640608) and the National High Technology Research and Development Program of China (863 Program, AA635030), which we gratefully acknowledge.

\section{References}

[1] D.R. Vij, Luminescence of Solids, Plenum Press, New York, USA, 1998 , p. 391.

[2] W. Adam, G. Cilento (Eds.), Chemical and Biological Generation of Excited States, Academic, New York, USA, 1982.

[3] D.M. Hercules, M. Cormier, J. Lee (Eds.), Chemiluminescence and Bioluminescence, Plenum Press, New York, USA, 1973.

[4] A.K. Campbell, Chemiluminescence: Principle and Applications in Biology and Medicine, Ellis Horwood, Chichester, UK, 1988.

[5] J.W. Birks, Chemiluminescence and Photochemical Reaction in Chromatography, VCH Publishers, New York, USA, 1989.

[6] L.J. Blum, Bio- and Chemi-Luminescent Sensors, World Scientific, Singapore, 1997.

[7] A. Roda, M. Pazzagli, L.J. Kricka, P.E. Stanley (Eds.), Bioluminescence and Chemiluminescence Perspectives for the 21st Century, John Wiley \& Sons, Chichester, UK, 1999.

[8] A.R. Bowie, M.G. Sanders, P.J. Worsfold, J. Biolumin. Chemilumin. 11 (1996) 61

[9] J.-M. Lin, M. Ishii, M. Yamada, Bunseki (1998) 865.

[10] J.-M. Lin, M. Yamada, Recent Res. Devel. Pure Appl. Anal. Chem. 1 (1998) 133.

[11] M. Grätzel, K. Kalyanasundaram, Surf. Sci. Ser. 38 (1991) 1.

[12] K. Kalayasundram, Photochemistry in Microheterogeneous Systems, Academic Press, New York, USA, 1987.

[13] W.L. Hinze, N. Srinivasan, T.K. Smith, S. Igarashi, H. Hoshino, in: I.M. Warmer, L.B. McGown (Eds.), Organized Assemblies in Analytical Chemiluminescence Spectroscopy: An Overview in Advances in Multidimensional Luminescence, JAI Press, Greenwich, CT, USA, 1990.

[14] E. Pramauro, E. Pelizitti, in: S.G. Weber (Editor), Comprehensive Analytical Chemistry, Vol. XXXI, Surfactants in Analytical Chemistry, Elsevier, Amsterdam, The Netherlands, 1996.

[15] P. Mukerjee, K.J. Mysels, Critical Micelle Concentrations of Aqueous Surfactant Systems, NSRDS-NBS-36, Washington, DC, USA, 1971. 
[16] W. L. Hinze, in: K.L. Mittai (Eds.), Solution Chemistry of Surfactants, Plenum, New York, USA, 1979, pp. 79-127, and references therein.

[17] C.M. Paleos, G. Vassilopoulos, J. Nikokavouras, J. Photochem. 18 (1982) 327.

[18] S. Shinkai, Y. Ishikawa, O. Manabe, T. Kunitake, Chem. Lett. (1981) 1523.

[19] M. Yamada, S. Suzuki, Anal. Lett. 17 (1984) 251.

[20] M. Ishii, M. Yamada, S. Suzuki, Bunseki Kagaku 35 (1986) 373.

[21] M. Ishii, M. Yamada, S. Suzuki, Bunseki Kagaku 35 (1986) 379.

[22] K.H. Coale, K.S. Johnson, Anal. Chim. Acta 266 (1992) 345.

[23] K. Watanabe, T. Yamasaki, M. Itagaki, Bunseki Kagaku 45 (1996) 407.

[24] K. Watanabe, T. Yamasaki, M. Itagaki, Bunseki Kagaku 45 (1996) 897.

[25] K. Watanabe, H. Miyamoto, M. Itagaki, Bunseki Kagaku 48 (1999) 705.

[26] M. Kato, M. Yamada, S. Suzuki, Anal. Chem. 56 (1984) 2529.

[27] M. Yamada, H. Kanai, S. Suzuki, Bull. Chem. Soc. Jpn. 58 (1985) 137.

[28] W.L. Hinze, T.E. Riehl, H.N. Singh, Y. Baba, Anal. Chem. 56 (1984) 2180.

[29] L.L. Klopf, T.A. Nieman, Anal. Chem. 56 (1984) 1539.

[30] T. Kamidate, T. Kaneyasu, T. Segawa, H. Watanabe, Bull. Chem. Soc. Jpn. 64 (1991) 1991.

[31] T. Kamidate, T. Kaneyasu, T. Segawa, H. Watanabe, Chem. Lett. (1991) 1719.

[32] A. Ingvarsson, C.L. Flurer, T.E. Riehl, K.N. Thimmaiah, J.M. Williams, W.L. Hinze, Anal. Chem. 60 (1988) 2047.

[33] M.S. Abdel-Latif, G.G. Guilbault, Anal. Chim. Acta 221 (1989) 11.

[34] P. Mikuska, Z. Vecera, Anal. Chim. Acta 410 (2000) 159.

[35] T. Kamidate, H. Ichihashi, T. Segawa, H. Watanabe, J. Biolumin. Chemilumin. 10 (1995) 55.

[36] O.M. Steijger, H.M. Van Mastbergen, J.J.M. Holthuis, Anal. Chim. Acta 217 (1989) 229.

[37] M. Ishii, Y. Ohno, T. Hobo, Anal. Sci. 7 (1991) 873.

[38] G.M. Greenway, L.J. Nelstrop, S.N. Port, Anal. Chim. Acta 405 (2000) 43.

[39] J. Ouyang, A.J. Bard, Bull. Chem. Soc. Jpn. 61 (1988) 17.

[40] G.N. Chen, J.P. Duan, Q.-F. Fu, Microchim. Acta 116 (1994) 227.

[41] Z.-H. Xie, F. Zhang, Y.-S. Pan, Analyst (Cambridge, UK) 123 (1998) 273.

[42] M. Yamada, S. Suzuki, Anal. Chim. Acta 193 (1987) 337.

[43] H. Oshima, M. Yamada, S. Suzuki, Anal. Chim. Acta 232 (1990) 385.

[44] Y.Huang, C.Zhang, X.Zhang, Anal. Chim. Acta 391 (1999) 95.

[45] G.-F. Zhang, H.-Y. Chen, Anal. Chim. Acta 409 (2000) 75.

[46] T.E. Riehl, C.L. Malehorn, W.L. Hinze, Analyst (Cambridge, UK) 111 (1986) 931.

[47] J. Lasovsky, F. Grambal, Bioelectrochem. Bioenerg. 15 (1986) 95.

[48] N. Dan, M.L. Lau, M.L. Grayeski, Anal. Chem. 63 (1991) 1766.

[49] W.L. Hinze, N. Srinivasan, T.K. Smith, S, Igarashi, H. Hoshino, in: I.M. Warner, L.B. McGown (Eds.), Advances in Multidimensional Luminescence, JAI Press, Greenwich, CT, USA, 1991, pp. 149-206, and references therein.

[50] M.P. Pileni, Structure and Reactivity in Reverse Micelles, Elsevier, Amsterdam, The Netherlands, 1989.

[51] H. Hoshino, W.L. Hinze, Anal. Chem. 59 (1987) 496.

[52] S. Igarashi, W.L. Hinze, Anal. Chem. 60 (1988) 446.

[53] T. Fujiwara, N. Tanimoto, J.J. Huang, T. Kumamaru, Anal. Chem. 61 (1989) 2800.
[54] T. Fujiwara, N. Tanimoto, K. Nakahara, T. Kumamaru, Chem. Lett. (1991) 1137.

[55] T. Fujiwara, T. Theingi-Kyaw, T. Kumamaru, Anal. Sci. 13 (1997) 59.

[56] T. Imdadullah, T. Fujiwara, T. Kumamaru, Anal. Chem. 63 (1991) 2348.

[57] T. Imdadullah Fujiwara, T. Kumamaru, Anal. Sci. 7 (1991) 1399.

[58] T. Imdadullah Fujiwara, T. Kumamaru, Anal. Chem. 65 (1993) 421.

[59] T. Fujiwara, K. Murayama, T. Imdadullah Kumamaru, Microchem. J. 49 (1994) 183.

[60] T. Imdadullah Fujiwara, T. Kumamaru, Anal. Chim. Acta 292 (1994) 151.

[61] T. Theingi-Kyaw, T. Fujiwara, H. Inoue, Y. Okamoto, T. Kumamaru, Anal. Sci. 14 (1998) 203.

[62] S. Theingi-Kyaw Kumooka, Y. Okamato, T. Fujiwara, T. Kumamaru, Anal. Sci. 15 (1999) 293.

[63] T. Fujiwara, I.U. Mohammadzai, K. Murayama, T. Kumamaru, Anal. Chem. 72 (2000) 1715.

[64] T. Fujiwara, I.U. Mohammadzai, H. Inoue, T. Kumamaru, Analyst (Cambridge, UK) 125 (2000) 759.

[65] J. Hayashi, M. Yamada, T. Hobo, Anal. Chim. Acta 247 (1991) 27.

[66] J. Hayashi, M. Yamada, T. Hobo, Anal. Chim. Acta 259 (1992) 67.

[67] J. Hayashi, M. Yamada, T. Hobo, Anal. Chim. Acta 266 (1992) 359.

[68] N. Dan, M.L. Grayeski, Langmuir 10 (1994) 447.

[69] T. Kamidate, M. Katoh, T. Segawa, H. Watanabe, Chem. Lett. (1994) 113.

[70] M.L. Das, P.K. Bhattacharya, S.P. Moulik, Langmuir 6 (1990) 1591.

[71] J. Leis, J.C. Mejuto, M.E. Pena, Langmuir 9 (1993) 889.

[72] L. Mukhopadhyay, N. Mitra, P.K. Bhattacharya, S.P. Moulik, Langmuir 11 (1995) 2866.

[73] D. Langevin, Acc. Chem. Res. 21 (1988) 255.

[74] F.M. Menger, Angew. Chem. Int. Ed. Engl. 30 (1991) 1086.

[75] M.P. Savelli, C. Solans, R. Pons, M. Clausse, P. Erra, Colloids Surf. A 119 (1996) 155.

[76] F.M. Menger, A.R. Elrington, J. Am. Chem. Soc. 113 (1991) 9621.

[77] S.-G. Oh, J. Kizling, K. Holmberg, Colloids Surf. A 97 (1995) 169.

[78] S.-G. Oh, J. Kizling, K. Holmberg, Colloids Surf. A 104 (1995) 217.

[79] S. Gutfelt, J. Kizling, K. Holmberg, Colloids Surf. A 128 (1997) 265.

[80] B. Du, Q. Wei, S. Wang, W. Yu, Talanta 44 (1997) 1803.

[81] A.S. Carretero, C.C. Blanco, A.F. Gutierrez, Analyst (Cambridge, UK) 122 (1997) 925.

[82] R.B. Thompson, S.E. Shaw-McBee, Langmuir 4 (1988) 106.

[83] A.V. Puchkaev, D.I. Metelitsa, Biokhimiya (Moscow) 58 (1993) 1538.

[84] S. Cohen, S. Magdassi, Langmuir 12 (1996) 3759.

[85] A. Kamyshny, S. Magdassi, Colloids Surf. B 11 (1998) 249.

[86] N. Ishimaru, J.-M. Lin, M. Yamada, Anal. Commun. 35 (1998) 67.

[87] R.M. Mandle, Y.N. Wong, U.S. Pat. 4,372,745, 1983.

[88] J.M. Hubry, Fr. Pat. 3891-870-320, 1987.

[89] R. Thompson, U.S. Pat. 253,635, 1988.

[90] R. Thompson, U.S. Pat. 849,251, 1993.

[91] S.S. Tseng, A.G. Mohan, L.G. Haines, L.S. Vizcarra, M.M. Rauhut, J. Org. Chem. 44 (1979) 4113. 